\title{
OS ESTUDOS LEGISLATIVOS BRASILEIROS: DO CONGRESSO NACIONAL AOS MUNICÍPIOS
}

\author{
Matheus Jones Zago ${ }^{1}$ \\ Anna Paula de Moraes Bennech² \\ Edilson José Graciolli ${ }^{3}$
}

\begin{abstract}
Resumo
O campo de pesquisa sobre os Estudos Legislativos brasileiros é amplo, abarcando análises institucionais e estudos sobre as relações entre Legislativo e Executivo, Legislativo e Judiciário. Ademais, há investigações sobre elites políticas, representação política, análise da atuação de Deputados, Senadores e Vereadores, bem como de suas trajetórias políticas e formas de poder em perspectiva histórica e sociológica. O objetivo deste artigo é apresentar uma discussão teórica sobre Estudos Legislativos na Ciência Política brasileira, com especial atenção para a agenda de pesquisa sobre os municípios. Como metodologia, foi realizado um levantamento bibliográfico de pesquisas sobre os Estudos Legislativos no Brasil. O resultado da revisão de literatura comprova a relevância dos Estudos Legislativos para análises em âmbito nacional e local a respeito da relação entre poderes, representação parlamentar e desenvolvimento da democracia. Ainda, conclui-se que esses estudos legislativos necessitam abranger as três esferas federativas, sendo os estudos Legislativos municipais uma pauta essencial para a Ciência Política brasileira.
\end{abstract}

Palavras-chave: Estudos Legislativos. Municípios. Poder Local.

\section{Brazilian legislative studies: from the national congress to municipalities}

\begin{abstract}
The research on Brazilian Legislative Studies is broad, encompassing institutional analyses and studies on the relations between the Legislative and Executive, Legislative and Judiciary. Moreover, it includes studies on political elites, political representation, analysis of the actions of deputies, senators, and council members, as well as their political trajectories and forms of power from a historical and sociological perspective. This paper aims to present a theoretical discussion on Legislative Studies in Brazilian Political Science, with distinctive attention to the research agenda on municipalities. The methodology consists of a literature review on Brazilian Legislative Studies. The results prove the relevance of Legislative Studies for analysis at the national and local levels regarding the relationship between powers, parliamentary representation, and the development of democracy. Furthermore, it concludes that legislative studies need to cover the three federal spheres, with the local legislative studies being an essential agenda for Brazilian Political Science.
\end{abstract}

Keywords: Legislative Studies. Municipality. Local Power.

\footnotetext{
${ }^{1}$ Matheus Jones Zago, doutorando em Ciência Política pela Julius-Maximilians-Universität Würzburg (JMU). E-mail: mjzago@gmail.com

${ }^{2}$ Anna Paula de Moraes Bennech, doutoranda em Ciência Política pela Julius-Maximilians-Universitäł Würzburg (JMU). E-mail: annabennech@gmail.com

${ }^{3}$ Dr. Edilson José Graciolli, professor titular no Instituto de Ciências Sociais da Universidade Federal de Uberlândia (UFU). E-mail: egraciolli@ufu.br
} 


\section{Introdução}

Os Estudos Legislativos são um campo rico e plural de investigação na Ciência Política. O livro The Oxford Handbook of Legislative Studies (MARTIN; SAALFELD; STR $\varnothing M, 2014$ ) apresenta uma longa descrição e uma variedade de disciplinas acadêmicas que abordam os Estudos Legislativos e suas atividades. Este objeto de estudo possui uma longa tradição nas escolas do pensamento, incluindo Filosofia, História, Direito e, desde a segunda metade do século XX, Ciência Política.

Nos últimos 50 anos, os Estudos Legislativos se tornaram uma das maiores subáreas da Ciência Política. Muitas associações nacionais e internacionais (como American Political Association, Political Studies Association, International Political Science Association e European Consortium for Political Research) dedicaram seções completas aos Estudos Legislativos, com uma imensa variedade de publicações em jornais internacionais. Consolidaram-se, também, jornais científicos especializados nos Estudos Legislativos (como Parliamentary Affairs [1947], Zeitschrift fur Parlamentsfragen [1969], Legislative Studies Quarterly [1976], Australasian Parliamentary Review [1986] ou The Journal of Legislative Studies [1995]) (MARTIN; SAALFELD; STR ØM, 2014).

Há, ainda, vasta literatura sobre o Congresso dos Estados Unidos (instituição que concentra o maior números de trabalhos na área da Ciência Política), importante para entender o funcionamento do Poder Legislativo (de forma institucional e política) e suas decisões que afetam diretamente a vida democrática. Pesquisadores do tema desenvolveram metodologias capazes de mensurar formas de avaliação e desempenho do Poder Legislativo, assim como o poder de sua capacidade representativa. Esses estudos desempenham papel essencial para o entendimento da produção legislativa e merecem rigor analítico e tratamento científico dos dados empíricos, uma vez que podem oferecer resultados com potencial para o fortalecimento de práticas democráticas.

No contexto brasileiro, todavia, os primeiros trabalhos sobre política e economia, de modo geral, deixaram em segundo plano, ou até ignoraram, o parlamento e os seus órgãos legislativos como arenas relevantes para debates e tomada de decisões. Inicialmente, o que significa antes da Constituição de 1988, poucos trabalhos evidenciaram teorias claras sobre o papel do Poder Legislativo e a sua capacidade de representação. Com o fim da ditadura militar e a reinstauração da democracia, crescem e desenvolvem-se os 
Estudos Legislativos no Brasil, assim como ampliam-se as pesquisas que versam diretamente sobre o Poder Legislativo em âmbito nacional e regional. Entretanto, a pesquisa em âmbito local permanece, ao longo do tempo, ainda em segundo plano.

É a partir dessa reflexão que este artigo se propõe a apresentar uma discussão teórica sobre a Ciência Política brasileira e os Estudos Legislativos, em especial a agenda de pesquisa sobre os municípios. A revisão bibliográfica é dividida em dois momentos: primeiramente, discute-se os Estudos Legislativos que versam majoritariamente sobre o Legislativo federal e estadual antes e após a Constituição de 1988; o segundo momento é dedicado a debater a abordagem local.

\section{A ciência política brasileira e uma abordagem nacional e regional dos estudos legislativos}

Os estudos em Ciência Política relacionam-se e estão permeados pelo contexto histórico e social do objeto de estudo e do recorte temporal metodológico escolhidos. Nesse sentido, abordagens podem apresentar diferentes resultados, quando, por exemplo, analisa-se a produção legislativa de um determinado período, o comportamento disciplinado de parlamentares em determinada legislatura ou as relações de poderes em determinada esfera. Consideradas essas questões, este tópico é dedicado a apresentar como a Ciência Política brasileira abordou os Estudos Legislativos: no primeiro subtópico, o enfoque recai sobre a agenda de pesquisa antes da promulgação da Constituição de 1988, também chamada de Constituição Cidadã, enquanto o segundo subtópico versa sobre o período pós-redemocratização.

\subsection{Estudos legislativos pré Constituição de 1988}

Até o final do regime militar, poucas pesquisas trataram sobre 0 funcionamento e as características do Poder Legislativo. Segundo Sérgio Soares Braga (2008), parte dos trabalhos sobre política e economia entre 1945-1964 ignora o Parlamento e os órgãos legislativos como arenas relevantes para debates e tomada de decisões. Ainda, deixam em segundo plano as análises sobre o papel do Legislativo, dos partidos políticos e das relações institucionais na discussão e na elaboração de políticas. Para Braga (2008), os autores do período se interessam "predominantemente pela repercussão de tais relações no desempenho do sistema

CSOnline - Revista Eletrônica de Ciências Sociais, Juiz de Fora, n. 32 (2020). 
político no sentido estrito do termo" (BRAGA, 2008, p. 14). Assim, apenas indiretamente tais estudos abordam o papel relativo do Executivo e do Legislativo no processo de tomada de decisões da época.

Como primeiros trabalhos que envolvem a temática antes do período militar, Braga (2008) destaca os estudos de Trigueiro (1959), sobre a "crise legislativa" e a incapacidade do Parlamento de produzir uma legislação relevante; de Mello Franco, cuja a tese aponta o Congresso como um ator irrelevante e subalterno ao presidente da República; Furtado (1965 apud BRAGA, 2008) e a existência de uma "hipertrofia do Executivo"; e Pereira (1961) sobre o papel do Legislativo durante a Constituinte de 1946 como obstáculo à execução de reformas de base nacionalistas e distributivas para o desenvolvimento econômico e social do país.

Já logo após o golpe de 1964, Braga (2008) também menciona o estudo clássico de Furtado (1965) sobre as relações entre o Legislativo e o "desenvolvimento" econômico no período 19451964; o trabalho enxerga o papel do Legislativo "como principal obstáculo ao crescimento econômico". Para Furtado, o Congresso Nacional poderia ser visto como um centro de poder dominado por "interesses particulares", controlado por "oligarquias regionais" que legitimam uma política econômica excludente, capaz de manter o país em uma situação de subdesenvolvimento (FURTADO, 1965 apud BRAGA, 2008). De maneira semelhante a Furtado, a tese de Gabriel Cohn (1968) aponta que, após a redemocratização ocorrida em 1946, a restauração dos órgãos legislativos foi responsável pela presença de novos atores políticos, que se comportaram como obstáculos para a implementação de uma "política de desenvolvimento".

Com uma perspectiva diferente, Clóvis Brigagão (1973) analisou os Projetos Lei (PLS) propostos e aprovados pelo Congresso brasileiro entre os anos de 1959 e 1966. O resultado obtido permitiu ao autor afirmar que o Poder Legislativo não funcionou como obstáculo à aprovação da agenda do Executivo, conforme afirmaram Furtado (1965 apud BRAGA, 2008) e Cohn (1968), pois as taxas de aprovação de PLs do Executivo mantiveram-se altas por todos os períodos governamentais. Ademais, o autor comprovou que a aprovação de projetos de lei variou de partido para partido. Na mesma linha, Sérgio Henrique Abranches (1973 apud BRAGA, 2008) criticou a visão do Legislativo como "obstáculo institucional". Para o autor, o Congresso Nacional se comportou como um espaço político de articulação de um novo sistema de ação em um

CSOnline - Revista Eletrônica de Ciências Sociais, Juiz de Fora, n. 32 (2020). 
contexto de "crise de hegemonia", cuja função, no entanto, é eminentemente "conservadora" (BRIGAGÃO, 1973; ABRANCHES, 1973 apud BRAGA, 2008).

De acordo com Braga (2008), no período ditatorial, a literatura sobre - Legislativo trouxe estudos de pesquisadores e autoridades governamentais sobre a temática geral de relações entre o "Legislativo e o Desenvolvimento". Entretanto, esses trabalhos apresentaram "poucas evidências sistemáticas sobre o processo decisório e elaboração legal no período" (BRAGA, 2008, p. 21).

Não há uma constante no que concerne os regimes políticos de governo no Brasil, cuja trajetória republicana conta com alternância entre períodos autoritários e outros democráticos. 0 desenvolvimento das instituições legislativas democráticas, dessa forma, é atravessado por intervenções discricionárias, o que reflete na relativa escassez de estudos sobre o Legislativo brasileiro antes da promulgação da Constituição de 1988, conforme pode-se observar nesta seção. A seção seguinte, por sua vez, trata sobre a crescente em pesquisas sobre o Poder Legislativo a partir da reinstauração da democracia no Brasil.

\subsection{Estudos legislativos pós-redemocratização}

A agenda de pesquisa sobre os Estudos Legislativos é impulsionada, principalmente, pela transição democrática. O período de desenvolvimento dos Estudos Legislativos no Brasil acontece, sobretudo, após o final do regime ditatorial, em que muitos pesquisadores preocuparam-se em analisar as características das instituições do novo período democrático.

Uma gama de estudos sobre Congresso Nacional, Câmara dos Deputados e Câmaras Municipais são impulsionados, em especial, pelo projeto pioneiro de Argelina Figueiredo e Fernando Limongi4, sediado no Centro Brasileiro de Análise e Planejamento (Cebrap). Além disso, as pesquisas recentes são fortemente influenciadas pela escola neoinstitucionalista, levando à revisão de uma série de teses convencionais sobre o papel do Legislativo e dos partidos políticos no sistema político brasileiro.

\footnotetext{
${ }^{4}$ Figueiredo e Limongi são pesquisadores pioneiros sobre as relações Executivo-Legislativo no Brasil, principalmente através do projeto intitulado "terra incógnita", um importante marco no campo da Ciência Política. Os estudos apresentaram uma sequência de pesquisas sistemáticas sobre o tema e eliminaram de vez muitos juízos negativos e afirmações sem embasamento empírico.
}

CSOnline - Revista Eletrônica de Ciências Sociais, Juiz de Fora, n. 32 (2020). 
Quanto ao fim da ditadura militar, Manuel Santos (2008) afirma que a redemocratização do país e, especialmente, a nova ordem constitucional inaugurada em 1988 possibilitaram, para a Ciência Política brasileira, um esforço coletivo para produzir explicações sobre nossas instituições políticas. É nesse contexto que o Poder Legislativo se torna um privilegiado objeto de estudo.

De acordo com Limongi (2010) e Manuel Santos (2008), as pesquisas sobre os Estudos Legislativos funcionam como suporte para a estruturação de uma discussão acadêmica centrada no funcionamento efetivo do novo sistema político brasileiro. Segundo Limongi (2010), os Estudos Legislativos se inserem em um debate sobre a consolidação da democracia em perspectivas distintas. Assim, os trabalhos na área apresentam duas diferentes visões: fortalecimento ou fragilização da democracia como resultado de uma longa transição política e uma paulatina adoção de mecanismos típicos de regimes democráticos.

As reflexões a respeito dos órgãos legislativos ressaltam, em geral, as particularidades do processo decisório, como a relação entre os poderes Executivo e Legislativo, as características de partidos políticos, o perfil e o comportamento político dos parlamentares, as proposições legislativas e as tomadas de decisão. Nos regimes democráticos, as propostas apresentadas em cada legislatura e a produção legislativa constituem-se como recursos valiosos, podendo influenciar a agenda legislativa, assim como a direção e o alcance de políticas públicas (ALEMÁN; TSEBELIS, 2016).

Para Santos (2008), é possível testar e aplicar conceitos que explicam o funcionamento e a eficiência das instituições políticas no país. Estudos comparativos também podem ser realizados, permitindo examinar o Legislativo sob diferente óticas: formas de governo (presidencialismo vs, parlamentarismo); sistemas eleitorais (voto partidário $v s$. voto pessoal); e processo decisório (centralização vs. descentralização). Ademais, é possível a análise da relação do Poder Legislativo com outros poderes e atores.

Uma vasta literatura sobre o Legislativo é produzida na Ciência Política no início da década de 1990. O foco recai sobre as relações entre Executivo-Legislativo ${ }^{5}$ (LIMONGI, 1994; FIGUEIREDO; LIMONGI,

\footnotetext{
${ }^{5}$ Grande parte das pesquisas que abordam o desempenho do Executivo Legislativo no Brasil trata da relação de aprovação/reprovação de propostas enviadas à Câmara ou ao Congresso. As pesquisas apontam para um consenso acerca do predomínio do Executivo na produção legal e ainda demonstram mecanismos institucionais que permitem colocar em vantagem as propostas do Executivo. Como exemplo, observa-se o alto número de medidas provisórias aprovadas, os pedidos de solicitações de urgência em tramitação de Projetos de Lei, além da centralização de decisões importantes nas figuras dos líderes de partido (ARAúJO; SILVA, 2012).
}

CSOnline - Revista Eletrônica de Ciências Sociais, Juiz de Fora, n. 32 (2020). 
1999; SANTOS, 2003; PEREIRA; MUELLER, 2002; AMORIM NETO, 2000; AMORIM NETO; TAFNER, 2002), sendo que os trabalhos estão dispostos em revistas e jornais especializados no tema, como: Revista Brasileira de Informação Bibliográfica em Ciências Sociais (BIB); DADOS - Revista de Ciências Sociais; ANPOCS-RBCS - Revista Brasileira de Ciências Sociais; RSP - Revista de Sociologia e Política; Perspectivas - Revista de Ciências Sociais; e Novos Estudos Cebrap.

Estudos sobre o perfil social e a trajetória política dos parlamentares também integram a agenda de pesquisa sobre os Estudos Legislativos. A composição social e a trajetória política dos parlamentares eleitos ao longo do tempo trazem dados importantes para a compreensão do nosso sistema representativo. Indicadores de tempo de carreira, tipo de cargo ocupado, base eleitoral, posição ideológica e ocupação profissional antes do pleito, por exemplo, são algumas das variáveis utilizadas.

Leôncio Martins Rodrigues (2006), em seu estudo clássico, apresenta a crescente profissionalização e personalização da classe política brasileira, destacando os altos índices de políticos com passagem no funcionalismo público. Da mesma forma, Paulo Magalhães Araújo (2013) realiza um levantamento sobre o perfil social dos parlamentares da $48^{a}$ até a $52^{a}$ legislatura, destacando a subrepresentação feminina nas casas legislativas. Em paralelo, o autor ainda aponta as ocupações profissionais, a idade madura e o alto nível de instrução dos parlamentares, em especial no Senado brasileiro.

André Marenco dos Santos (2000), por sua vez, levanta dados biográficos dos deputados federais brasileiros empossados no período pré e pós-ditatorial, uma pesquisa significativa em termos de análise de características e recorte temporal. $O$ resultado encontrado pelo autor evidencia uma característica marcante: o fato de os deputados construírem sua carreira política sem necessitarem exclusivamente dela para sobreviver. De forma semelhante, Fabiano Santos (2000) organiza informações sobre a carreira política de parlamentares empossados de 1946 até 1999. O resultado demonstra que uma significativa quantidade de deputados federais inicia sua carreira política nas Assembleias Estaduais ou prefeituras.

Trabalhos sobre o perfil dos atores políticos são desenvolvidos em paralelo com os estudos de elites políticas (SANTOS, 1997 e 2000; KERBAUY, 2005; PERISSINOTTO et al. 2007; CODATO, 2008; RODRIGUES, 2006). Outros trabalhos evidenciam as taxas de

CSOnline - Revista Eletrônica de Ciências Sociais, Juiz de Fora, n. 32 (2020). 
renovação das cadeiras no congresso de forma diretamente relacionada ao perfil dos parlamentares (SANTOS, 2003; PEREIRA; RENNÓ, 2001; ARAÚJO, 2013; FIGUEIREDO; LIMONGI, 1996).

A revisão de literatura feita até aqui permite identificar que, após a redemocratização, destaca-se o aumento do interesse da Ciência Política brasileira sobre os Estudos Legislativos de modo geral, com ênfase nas relações entre os poderes, assim como nos perfis e no comportamento de parlamentares. A retomada da democracia, portanto, impulsiona as pesquisas sobre as características, as funções e as relações das instituições políticas brasileiras. Desse modo, constitui-se o Legislativo como uma relevante frente de pesquisa, dado seu caráter indispensável à democracia.

O enfoque desses estudos, contudo, possui majoritariamente as casas legislativas federais como protagonistas, sendo coadjuvantes os legislativos estaduais e municipais. Isso acontece ainda que os municípios tenham sido matéria preponderante na engenharia institucional implementada pela Constituição Cidadã. A próxima seção, considerada essa perspectiva, versa sobre uma abordagem local dos Estudos Legislativos.

\section{Estudos legislativos municipais - uma abordagem local}

O restabelecimento do regime democrático no Brasil é marcado pela forte ampliação da autonomia local. Em 1988, os municípios brasileiros foram elevados a entes federativos da União. O fato representou um marco histórico no processo de descentralização política no país e atribuiu aos municípios competências importantes. Para Maria Teresa Miceli Kerbauy (2005), a capacidade em criar leis próprias (leis orgânicas) e a relativa autonomia político-jurídica situam os municípios como relevantes atores no cenário político brasileiro.

O estudo da representação local se justifica, entre outras questões, pelo importante papel que os municípios, seus gestores e legisladores desempenham no país desde a promulgação da constituição. Em vista disso, é crescente o número de pesquisas que analisam o sistema político sob essa ótica. A relevância do tema também acompanha a "tendência internacional de valorizar os níveis subnacionais de governo" (KERBAUY, 2005, p. 338).

É possível afirmar que os estudos sobre o Congresso Nacional impulsionaram pesquisas tanto das Assembleias Legislativas quanto das Câmaras de Vereadores. As pesquisas sobre a representação

CSOnline - Revista Eletrônica de Ciências Sociais, Juiz de Fora, n. 32 (2020). 
política e o perfil dos governos locais e regionais (KERBAUY, 2005; CAETANO, 2005; D'ÁVILA FILHO; LIMA; JORGE, 2011; COUTO; ABRUCIO, 1995; BOSCHI, 1999) ampliaram o debate dos Estudos Legislativos na Ciência Política brasileira e trouxeram elementos fundamentais para a estruturação da disciplina em torno dos municípios.

Kerbauy (2005) assinala que, em geral, as pesquisas sobre o Legislativo em âmbito municipal evidenciaram os aspectos negativos da instituição, como, por exemplo, características seculares, baixa capacidade de legislar e fraca atuação diante do poder Executivo6. Félix Lopez (2004, p. 170), a título de exemplo, demonstra que a estrutura do sistema político local se apoia fortemente na troca de favores, nas redes de dependência pessoal e na solidariedade clientelista do Legislativo. $O$ autor, ao analisar a atividade política cotidiana dos Vereadores do município de Araruama-RJ, afirma que, sem o apoio do Executivo, os Vereadores ficariam impedidos de exercerem a função que julgam fundamental: "empreender as ações nas comunidades".

Do mesmo modo, ao verificarem a produção legislativa ordinária no município do Rio de Janeiro, Paulo D'Avila, Paulo Cesar G. de Cerqueira Lima e Vladimyr Lombardo Jorge (2011, p. 44-45) concluem que os vereadores participam de um jogo de "intermediação de interesses paroquiais", aprovando muitas indicações e homenagens, que permitem, entre outras coisas, maior grau de aprovação com o eleitorado e aumento da visibilidade na Câmara Municipal. As indicações, comumente vistas como "perfumaria" e produção legislativa insignificante, evidenciam-se como instrumentos de manutenção de redes políticas, sendo, por isso, importante sua análise.

Outras pesquisas sugerem que o forte poder de agenda dos membros do Poder Executivo, sobretudo em matérias de iniciativas exclusivas (expressas na lei orgânica do município), impedem o funcionamento do Legislativo local. Nessa perspectiva, Bruno Caetano (2005) apresenta prerrogativas institucionais que colocam os membros do Executivo em posição privilegiada quando comparados aos membros do Legislativo. Dentre os exemplos

\footnotetext{
6 Kerbauy (2005) também identifica relevância na produção legislativa oriunda dos vereadores. Segundo a autora, as principais análises sobre o Legislativo nos municípios demonstram as grandes diferenças entre rural e urbano, que marcam significativamente as práticas políticas locais. A autora também aponta que, em alguns casos, o Poder Legislativo local demonstra incentivos à participação política da sociedade civil, minimizando o patrimonialismo e a privatização da política, enfatizando os procedimentos participativos em detrimento da qualidade da decisão e da representação; um exemplo elencado são os conselhos municipais.
}

CSOnline - Revista Eletrônica de Ciências Sociais, Juiz de Fora, n. 32 (2020). 
citados, estão a capacidade do Poder Executivo em vetar projetos e de nomear secretários municipais e subprefeitos. No levantamento realizado por Caetano (2005), quase a totalidade da produção legislativa em âmbito municipal se integrava no leque de preferências do prefeito?.

Ainda, existem estudos que dedicam-se a apresentar $O$ desempenho do Legislativo na arena decisória (ANDRADE, 1998; COUTO, 1998; CAETANO, 2005; D’ÁVILA FILHO; LIMA; JORGE, 2011). Outras pesquisas, por sua vez, demonstram práticas de clientelismo, mandonismo, paternalismo e hipertrofia do Poder Executivo, com relações de dependência político partidária dos governos locais para com os governos estaduais. Uma parte da literatura sobre o poder local concentrou esforços no entendimento da organização partidária e na capacidade dos partidos de influenciar as decisões dos vereadores (KERBAUY, 2008; BRAGA; PIMENTEL JR., 2013; COUTO, 1998).

O trabalho de Carolina Mattos Roeder (2016), ainda na mesma linha de pesquisa, verifica que o controle exercido pelo Poder Executivo nos municípios cria incentivos para que os Vereadores se unam ao governo municipal, apoiando a sua agenda. A autora refuta a hipótese de que o Poder Executivo local com uma base de sustentação dividida (ou seja, um governo sem maioria partidária na Câmara) possuiria relações deficientes com o Legislativo, limitando a aprovação de projetos importantes para a gestão ${ }^{8}$.

De forma semelhante, Matheus Jones Zago (2018) analisa o processo legislativo da Câmara Municipal de Uberlândia-MG. O autor destaca que, durante os três primeiros anos de legislatura, o contingente de leis (complementares e ordinárias) com origem no Poder Executivo é visivelmente superior ao do Poder Legislativo.

\footnotetext{
${ }^{7}$ Caetano (2005) estudou as relações Executivo-Legislativo na Câmara Municipal de São Paulo entre os anos de 2001 e 2004. O autor identificou que o Executivo local tem preponderância na formulação e na aprovação da agenda dos trabalhos legislativos no plenário em relação aos projetos de lei devido à sua composição partidária majoritária. O autor ainda identificou que o prefeito possui grande poder de interferir nos trabalhos Legislativos, estando respaldado pelo Regimento Interno e a Lei Orgânica do Município. Para Caetano (2005), os poderes de agenda conferidos aos líderes partidários, aos presidentes das comissões e ao presidente da Câmara constrangem os vereadores a uma atuação em bases partidárias.

8 Roeder (2016) avaliou dois municípios durante o período de 2005 a 2008 (Contagem-MG) e 2009 a 2012 (Joinville-SC). Em comum, esses municípios passaram por gestão de prefeitos do PT e se enquadraram como municípios com mais de 500.000 habitantes e menos de um milhão. A pesquisa de Roder (2016) traz um levantamento muito interessante, visto que a maioria dos trabalhos na Ciência Política concentrou esforços na pesquisa de municípios com acima de 1 milhão de habitantes, preferencialmente nas capitais. A autora observou que o Poder Legislativo, tanto em Contagem como em Joinville, não se comportou como uma instância de veto, tampouco como uma barreira contra as ações do poder Executivo. O trabalho também destacou que não houve diferenças entre o período em que o Executivo contou com apenas uma minoria nas Câmaras Municipais, e quando ampliou essa base. Em todos os casos, os projetos do Poder Executivo foram aprovados.
}

CSOnline - Revista Eletrônica de Ciências Sociais, Juiz de Fora, n. 32 (2020). 
Porém, ao analisar o último ano de legislatura, esse número é invertido, passando o Poder Legislativo a aprovar mais leis do que o Poder Executivo. Essa guinada está relacionada às tentativas de reeleição e à visibilidade dos membros do poder Legislativo?.

No campo da antropologia política, Karina Kuschnir (2000) analisa a questão legislativa sob um ponto de vista etnográfico. A autora discute o processo eleitoral e a representação política na cidade do Rio de Janeiro, dando ênfase às relações pessoais dos políticos com seus eleitores, o executivo municipal e a imprensa. Na mesma linha, Danilo César Souza Pinto (2013) faz uma análise dos processos simbólicos aprovados nas Câmaras Municipais de três localidades (Rio de Janeiro, São Paulo e Distrito Federal). O autor observa uma destacada quantidade de matérias, como denominação de logradouros e salas; simbologias; pedidos de convocação de sessões solenes e homenagens; datas comemorativas; e criação de honrarias figurando como parte essencial do processo legislativo. Ambos trabalhos contribuem para o debate sobre os Estudos Legislativos com discussões da área da antropologia política a respeito do funcionamento dos legislativos municipais.

Há, ainda, uma série de estudos de caso, organizados por Marta da Rocha Mendes e Kerbauy (2014), demonstrando a importância que municípios têm desempenhado na vida política do país. $O$ foco dessas pesquisas engloba estudos sobre competição eleitoral, perfil das elites políticas locais, organização partidária e produção legislativa local.

Com dados do Tribunal Superior Eleitoral (TSE), Bruno Souza Souza e Humberto Dantas (2016), em seu turno, analisam o perfil dos candidatos que venceram as eleições municipais para vereadores de 2000 a 2016 em todo Brasil. Os pesquisadores traçaram características de lideranças e das figuras políticas locais, mostrando discrepâncias na formação do pleito, disparidades de gênero, faixa etária e escolaridade, profissionalização da política local e acumulação de mandatos eleitorais.

Finalmente, esta seção permite apontar que estudos sobre o perfil dos parlamentares e o Legislativo (relações Executivo-Legislativo, produção legislativa, desempenho na arena decisória) revelaram

\footnotetext{
9 Zago (2018) analisou o processo legislativo da Câmara Municipal de Uberlândia e o perfil dos parlamentares da legislatura de 2013-2016. O autor verificou as relações entre os poderes Legislativo e Executivo em âmbito local através da análise dos principais atos normativos aprovados na Câmara Municipal e a capacidade de vereadores, partidos e coligações em atuar no processo decisório. A preponderância verificada do Poder Executivo no que concerne a aprovação de leis está em sintonia com outros trabalhos que estudam as relações Executivo e Legislativo (CAETANO, 2005; D'ÁVILA; LIMA; JORGE, 2011).
}

CSOnline - Revista Eletrônica de Ciências Sociais, Juiz de Fora, n. 32 (2020). 
dados significativos para a ampliação do debate sobre a democracia representativa no Brasil. Especificamente quando o enfoque é o nível local, as análises posicionam os municípios como elementos chave para a compreensão do atual arranjo institucional brasileiro. Os estudos legislativos, portanto, necessitam abranger as três esferas federativas (nacional, estadual e municipal), uma vez que as dinâmicas que regem 0 Congresso Nacional não necessariamente são replicadas para os diversos contextos que todo o Legislativo brasileiro comporta. Estudos Legislativos municipais, destarte, são uma pauta essencial para a Ciência Política brasileira.

\section{Considerações finais}

A partir de 1988, as pesquisas sobre os Estudos Legislativos se intensificam e muitos artigos, dissertações e teses sobre o tema foram desenvolvidos. As pesquisas, prevalentemente, concentramse em estudos que abrangem os âmbitos nacional e estadual, tratando temas como a relação entre os poderes Executivo e Legislativo, características de partidos políticos, perfil e comportamento político dos parlamentares, proposições legislativas e tomadas de decisão.

O crescimento do espaço destinado aos Estudos Legislativos na agenda de pesquisa da Ciência Política no período pósredemocratização influenciou e fomentou estudos sobre os municípios brasileiros. Os municípios, por serem entes federativos da União com grande poder de atuação na esfera local, contribuíram para a ampliação do debate sobre Estudos Legislativos no país. Pesquisas recentes sobre o funcionamento do Legislativo em âmbito local, em especial sobre a produção legislativa, perfil dos vereadores e relações Executivo vs. Legislativo, proporcionaram importantes dados para a mensuração de resultados e análise dessas instituições, seus membros e funcionamento.

É válido destacar que os estudos sobre o Poder Legislativo local têm direcionado suas pesquisas no eixo sul e sudeste e, preponderantemente, estão focados em capitais ou municípios de grande porte. De modo a enriquecer os trabalhos e as discussões na área, é vital a realização de estudos comparativos entre capitais e outros municípios de diferentes regiões do país. Estudos longitudinais envolvendo um maior recorte temporal também podem contribuir nessa perspectiva.

CSOnline - Revista Eletrônica de Ciências Sociais, Juiz de Fora, n. 32 (2020). 
De modo geral, os pesquisadores foram capazes de desenvolver metodologias e análises importantes para a compreensão do sistema político brasileiro em âmbito nacional e local. Os resultados da revisão de literatura especializada apontam na direção da formação de um campo fértil e promissor para o avanço nas análises da relação entre poderes e produção legislativa, incorporando outras dimensões como políticas públicas, elites políticas e processos eleitorais. Desse modo, os Estudos Legislativos, tanto local como nacional, se constituem enquanto um campo essencial para compreensão dessa dinâmica

\section{Referências}

ALEMÁN, Eduardo; TSEBELIS, George (eds.). Legislative Institutions and Lawmaking in Latin America. New York: Oxford University, 2016.

AMORIM NETO, Octavio. Gabinetes presidenciais, ciclos eleitorais e disciplina legislativa no Brasil. Dados, Rio de Janeiro, v. 43, n. 3, p. 479-519, 2000.

AMORIM NETO, Octavio; TAFNER, Paulo. Governos de Coalizão e Mecanismos de Alarme de Incêndio no Controle Legislativo das Medidas Provisórias. Dados, Rio de Janeiro, v. 45, n. 1, p. 5-38, 2002.

ANDRADE, Regis de Castro (org.). Processo de governo no município e no Estado. São Paulo: Universidade de São Paulo, 1998.

ARAÚJO, Paulo Magalhães. Parlamentares no Congresso Nacional: uma abordagem longitudinal e comparada do perfil de deputados e senadores brasileiros. $37^{\circ}$ Encontro Anual da ANPOCS. Anais... Vitória: Universidade Federal do Espírito Santo, 2013.

ARAÚJO, Suely; SILVA, Rafael. Reflexões e Novas Agendas de Pesquisa para os Estudos Legislativos no Brasil. Revista Ibero-Americana de Estudos Legislativos, $\mathrm{V}$. 2, p. 58-74. 2012.

BRAGA, Maria do Socorro; LEINE, Priscila; SABBAG, Gustavo. Partidos e representação na política local: perfil sócio-demográfico e vínculos políticopartidários dos vereadores paulistas. Colombia Internacional, v. 91, p. 117-150, 2017.

BRAGA, Maria do Socorro; PIMENTEL JR., Jairo. Estrutura e organização partidária municipal nas eleições de 2012. Cadernos ADENAUER, v. 2, p. 13-36, 2013.

BRAGA, Sérgio Soares. As relações entre o executivo e o Legislativo e a elaboração da política econômica na primeira experiência de democracia presidencialista pluripartidária brasileira (1946-1964). 2008. 285f. Tese (Doutorado em Desenvolvimento Econômico) - Universidade de Campinas, Campinas, 2008.

BRIGAGÃO, Clóvis. Poder e legislativo no Brasil: análise política da produção legal de 1959 a 1966. Rio de Janeiro. 1973. Dissertação (Mestrado em Ciência Política) - Departamento de Ciência Política, IUPERJ, Rio de Janeiro, 1973.

CSOnline - Revista Eletrônica de Ciências Sociais, Juiz de Fora, n. 32 (2020). 
CAETANO, Bruno. Executivo e legislativo na esfera local. Revista Novos Estudos Cebrap, São Paulo, n. 71, p. 101-125, mar. 2005.

COHN, G. Petróleo e nacionalismo. São Paulo: Difel, 1968.

COUTO, Cláudio G. Negociação, decisão e governo: padrões interativos na relação Executivo-Legislativo e o caso paulistano. In: ANDRADE, R. de C. (org.). Processo de governo no município e no Estado. São Paulo: Universidade de São Paulo, 1998.

COUTO, Cláudio G.; ABRUCIO, L. F. Governando a cidade? A força e a fraqueza da Câmara Municipal. São Paulo em Perspectiva, São Paulo, v. 9, n. 2, p. 57-65, 1995.

D'AVILA FILHO, Paulo. O que o conceito de clientelismo explica? Uma abordagem da tensão entre as dimensões normativa e volitiva da política. In: $\boldsymbol{6}^{\circ}$ Encontro Nacional da Associação Brasileira de Ciência Política. Sessão Temática Teoria Política coordenada por Wanderley Reis. Campinas: Associação Brasileira de Ciência Política, 2008.

D’AVILA FILHO, Paulo; LIMA, Paulo Cesar G. de Cerqueira; JORGE, Vladimyr Lombardo. Produção legislativa na Câmara Municipal de Rio de Janeiro: indicações, representação política e intermediação de interesses. Desigualdade e Diversidade - Dossiê Especial, segundo semestre, p. 185-206, 2011.

FIGUEIREDO, Argelina; LIMONGI, Fernando. Congresso Nacional: organização, processo legislativo e produção legal. Cadernos de Pesquisa Cebrap, São Paulo, n. 5, p. 5-18, 1996.

FIGUEIREDO, Argelina; LIMONGI, Fernando. Executivo e Legislativo na nova ordem constitucional. 1. ed. Rio de Janeiro: FGV, 1999.

KERBAUY, Maria Teresa Miceli. As câmaras municipais brasileiras: perfil de carreira e percepção sobre o processo decisório local. Opin. Pública, Campinas, v. 11, n. 2, p. 337-365, out. 2005. Disponível em: https://www.scielo.br/pdf/op/v11n2/26418.pdf. Acesso em: 09 jun. 2020.

KERBAUY, Maria Teresa Miceli. As Eleições Municipais de 2008: Federações Partidárias ou Partidos Nacionais. Perspectivas - Revista de Ciências Sociais, São Paulo, v. 35, p. 15-34, 2009. Disponível em:

https://periodicos.fclar.unesp.br/perspectivas/article/view/2286. Acesso em: 09 jun. 2020.

KERBAUY, Maria Teresa Miceli. Legislativo municipal, organização partidária e coligações partidárias. Cadernos Gestão Pública e Cidadania, v. 13, n. 53, p. 6583, jul./dez. 2008. Disponível em: http://bibliotecadigital.tse.jus.br/xmlui/handle/bdtse/4852. Acesso em: 09 jun. 2020.

KUSCHNIR, Karina. O cotidiano da política. Rio de Janeiro: Jorge Zahar, 2000.

LIMONGI, Fernando. Estudos Legislativos. In: LESSA, R. (org.), Horizontes das Ciências Sociais no Brasil: Ciência Política. São Paulo: ANPOCS, 2010. p. 163-189.

LIMONGI, Fernando. Modelos de Legislativo: o legislativo brasileiro em perspectiva comparada. Plenarium - Revista da Câmara dos Deputados, Brasília, n. 1, p. 4156, $2004 . \quad$ Disponível em: https://www.al.sp.gov.br/repositorio/bibliotecaDigital/20979_arquivo.pdf. Acesso em: 09 jun. 2020.

CSOnline - Revista Eletrônica de Ciências Sociais, Juiz de Fora, n. 32 (2020). 
LIMONGI, Fernando. O novo institucionalismo e os estudos legislativos: a literatura norte americana recente. BIB - Boletim Informativo e Bibliográfico de Ciências
Sociais,
n. 37 ,
p. 3-38,
1994.
Disponível
em:

http://www.anpocs.com/index.php/edicoes-anteriores/bib-37/444-o-novo-

institucionalismo-e-os-estudos-legislativos-a-literatura-norte-americana-

recente/file. Acesso em: 09 jun. 2020.

LOPEZ, Felix G. A política cotidiana dos vereadores e as relações entre executivo e legislativo em âmbito municipal: o caso do município de Araruama. Revista de Sociologia Política, Curitiba, n. 22, p. 153-177, jun. 2004. Disponível em: https://www.scielo.br/pdf/rsocp/n22/n22a12.pdf. Acesso em: 09 jun. 2020.

MARENCO DOS SANTOS, A. Não se fazem mais oligarquias como antigamente: recrutamento parlamentar, experiência política e vínculos partidários entre deputados brasileiros (1946-1998). 2000. 257f. Tese (Doutorado em Ciência Política) - Programa de Pós-graduação em Ciência Política, Universidade Federal do Rio Grande do Sul, Porto Alegre, 2000. Disponível em: https://lume.ufrgs.br/bitstream/handle/10183/77818/000297246.pdf?sequence $=1 \varepsilon$ isAllowed=y. Acesso em: 09 jun. 2020.

MARTIN, Shane; SAALFELD, Thomas; STR $\varnothing M$, Kaare. The Oxford Handbook of Legislative Studies. Oxford: Oxford University Press, 2014.

MELO FRANCO, A. A. Evolução da crise brasileira. São Paulo: Companhia Nacional, 1965.

MENDES, Marta da Rocha; KERBAUY, Maria Teresa Miceli. Eleições, partidos e representação política nos municípios brasileiros. Juiz de Fora: EdUFJF - Editora da Universidade Federal de Juiz de Fora, 2014.

PEREIRA, Carlos; MUELLER, Bernardo. Comportamento estratégico em presidencialismo de coalizão: as relações entre Executivo e Legislativo na elaboração do orçamento brasileiro. Dados, v. 45, n. 2, p. 265-301, 2002. https://doi.org/10.1590/S0011-52582002000200004

PEREIRA, Carlos; RENNÓ, L. O que é que o reeleito tem? Dinâmicas políticoinstitucionais locais e nacionais nas eleições de 1998 para a Câmara dos Deputados. Dados, v. 44, n. 2, p. 133-172, 2001. https://doi.org/10.1590/S001152582001000200004

PEREIRA, O. D. Quem faz as leis no Brasil? Rio de Janeiro: Civilização Brasileira, 1961.

PERISSINOTTO, R.; CODATO, A.; BRAGA, S. S.; FUKS, M. (Orgs). Quem governa? Um estudo das elites políticas no Paraná. Curitiba: UFPR, 2007.

PINTO, Danilo César Souza. Homenagens do legislativo: uma etnografia dos processos simbólicos do estado. 2013. 239 f. Tese (Doutorado em Ciências Humanas), Universidade Federal de São Carlos, São Carlos, 2013. Disponível em: https://repositorio.ufscar.br/bitstream/handle/ufscar/244/4929.pdf?sequence=18is Allowed=y. Acesso em: 09 jun. 2020.

RANGEL, Alan. Notas sobre os estudos legislativos dos municípios brasileiros: as diferentes abordagens metodológicas. Revista Eletrônica de Ciência Política, v. 4, n. $1-2$ 2013. Disponível em: https://revistas.ufpr.br/politica/article/view/33620/21579. Acesso em: 09 jun. 2020.

CSOnline - Revista Eletrônica de Ciências Sociais, Juiz de Fora, n. 32 (2020). 
RODRIGUES, Leôncio Martins. Mudanças na Classe Política Brasileira. 1. ed. São Paulo: Publifolha, 2006.

ROEDER, Carolina Mattos. Relação Executivo-Legislativo na esfera local: OS governos petistas em Contagem (MG) (2005 a 2008) e Joinville (SC) (2008 a 2012). 2016. 93f. Dissertação (Mestrado em Ciência Política) - Departamento de Ciência Política, Universidade Federal do Paraná, Curitiba, 2016. Disponível em: http://bibliotecadigital.tse.jus.br/xmlui/handle/bdtse/4078. Acesso em: 09 jun. 2020.

SANTOS, Fabiano Guilherme Mendes. Deputados federais e instituições legislativas no Brasil: 1946-99. In: BOSCHI, R.; DINIZ, E.; SANTOS, F. Elites políticas e econômicas no Brasil. São Paulo: Fundação Konrad Adenaver, 2000. p. 89-117.

SANTOS, Fabiano Guilherme Mendes. O Poder Legislativo no presidencialismo de coalização. Belo Horizonte: UFMG, 2003.

SANTOS, Fabiano Guilherme Mendes. Patronagem e poder de agenda na política brasileira. Dados, v. 40, n. 3, p. 465-491, 1997. https://doi.org/10.1590/S001152581997000300007

SANTOS, Manoel Leonardo. Teoria e método nos estudos sobre o Legislativo brasileiro: uma revisão da literatura no período 1994-2005. Revista Brasileira de Informação Bibliográfica em Ciências Sociais - BIB, São Paulo, n. 66, p. 65-89, $2^{\circ}$ sem. 2008. Disponível em: http://www.anpocs.com/index.php/edicoesanteriores/bib-66/614-teoria-e-metodo-nos-estudos-sobre-o-legislativo-

brasileiro-uma-revisao-da-literatura-no-periodo-1994-2005/file. Acesso em: 09 jun. 2020.

SILVA, Bruno Souza da; DANTAS, Humberto. Quem são eles? Identificando e caracterizando os vereadores brasileiros (2000-2016). Perspectivas: Revista de Ciências Sociais, São Paulo, v. 48, p. 11-45, jul./dez. 2016. Disponível em: https://periodicos.fclar.unesp.br/perspectivas/article/view/10906/7058. Acesso em: 09 jun. 2020.

TRIGUEIRO, Osvaldo. A crise legislativa e o regime presidencial. Revista Brasileira de Estudos Políticos, Belo Horizonte, n. 7 (extraordinário), p. 45-74, nov. 1959.

ZAGO, Matheus Jones. Os estudos do legislativo: ações e interações de poderes na Câmara Municipal de Uberlândia. 2015. 57f. Monografia (Graduação em Ciências Sociais) - Universidade Federal de Uberlândia, Uberlândia, 2015.

ZAGO, Matheus Jones. Produção Legislativa e Perfil dos Agentes Legislativos em Uberlândia - 2013 a 2016. 2018. 134 f. Dissertação (Mestrado em Ciências Sociais) - Universidade Federal de Uberlândia, Uberlândia, 2018. Disponível em: http://dx.doi.org/10.14393/ufu.di.2018.1325

CSOnline - Revista Eletrônica de Ciências Sociais, Juiz de Fora, n. 32 (2020). 